\title{
Removal of pesticides from soil by supercritical extraction-a preliminary study
}

\author{
Teresa Castelo-Grande*, Paulo A. Augusto, Domingos Barbosa \\ Departamento de Engenharia Química, Faculdade de Engenharia da Universidade do Porto, Pólo FEUP \\ do Centro de Biotecnologia e Química Fina, Rua Dr. Roberto Frias, 4200-465 Porto, Portugal
}

\begin{abstract}
The aim of this research project is to study the applicability of supercritical extraction with carbon dioxide to the decontamination of soils containing pesticides. In this work, after a brief but important introduction to the subject, the results of a preliminary study of the extraction of atrazine from sand with supercritical carbon dioxide are reported. These results, which were obtained with an extractor operated in batch mode, seem very promising, as a recovery of atrazine higher than $96 \%$ was obtained.
\end{abstract}

(C) 2005 Elsevier B.V. All rights reserved.

Keywords: Supercritical extraction; Soil decontamination; Pesticides; Atrazine; Solid matrices

\section{Introduction}

Since Second World War, pesticides have been used to help increasing agricultural production and preserve food quality for longer periods of time. In fact, the agricultural production during that period has doubled, and pesticides were responsible for $30 \%$ of that increase. Although pesticides have been benefiting agriculture by increasing production and fighting many plant and human diseases (such as malaria), their indiscriminate, and many times irresponsible use has made them an environmental problem. This is mainly due to their properties, such as high retention time in soil [1,2], low vapour pressure, moderate absorption by organic matter and clay [3], and high drainage potential, which leads to groundwater contamination. Thus, pesticides are two-edged swords, since they help to diminish hunger and fight some diseases, saving many lives, but their accumulation in ecosystems leads to their incorporation in the food chain, with all associated health problems. Some pesticides, such as atrazine, can exhibit phenomena called biomagnification, which consists on the ability of a pollutant to concentrate in animal tissues as it moves up in the food chain.

\footnotetext{
* Corresponding author. Tel.: +351 225081449 .

E-mail address: castelogrande@ sapo.pt (T. Castelo-Grande).
}

The soil, besides being an important support for all ecosystems, is a non-renewable natural resource, because the time necessary to form $1 \mathrm{~cm}$ of forest soil is estimated to be 200-400 years [4]. Nevertheless, its contamination by organic compounds such as polychlorinated biphenyls (PCBs) [5-9], polycyclic aromatic hydrocarbons (PAHs) [4,5,8-10] and pesticides [6,11-13,5], among others, is a growing problem, in spite of the increasing awareness of this fact by many countries.

In this work, a preliminary study of the possibility of using supercritical extraction to remove pesticides from soil is carried out. Atrazine was chosen for this study because it has been used in large scale around the world, in countries such as USA, Brazil, New Zealand, Germany and Portugal, and can be found in most of the contaminated soils, even in isolated areas around the globe [4].

\section{Atrazine}

Pesticides are classified, according to their purpose in sight as: bactericides, insecticides, fungicides, herbicides and others.

Atrazine (2-chloro-4-(ethylamino)-6-(isopropylamino)S-triazine), a white, crystalline solid, slightly volatile [14,15], is a herbicide from the group of the S-triazines (i.e., sym- 
metrical triazines), which was discovered in 1952 by scientists from J.R. Geigy Ltd. in Switzerland [16]. Its first application was done in 1954, being patented in 1955. The Striazines are strong inhibitors of the photosynthesis by interfering with the Hill reaction (which is a water-splitting (photolysis) light-initiated reaction that results in the production of free oxygen by the plants). Atrazine is used in corn, sugar cane, sorghum and pineapple cultures, among others [16], and presents slight to moderate toxicity for humans and other animals, causing abdominal pains, diarrhoea and vomits [17], being also considered potentially carcinogenic by the Environmental Protection Agency (EPA from USA) [18]. Atrazine has also the power to increase the toxicity of arsenic in human cells.

Due to its low vapour pressure and Henry constant, atrazine is easily drained, moving in the aqueous phase of the soil and contaminating the groundwater. Also, due to its $K_{\mathrm{ow}}$ value (water/octanol partition coefficient), atrazine is a herbicide that has the capacity to be adsorbed by organic matter, argyle and fat tissues. In 1988, more than half of the American states had the groundwater contaminated with atrazine $[19,20]$, while, for the surface water, it was estimated that the Mississippi river transported around $160 \mathrm{t}$ per year of atrazine to the Mexican Golf $[21,22]$. The main reason for the large use of atrazine, in spite of its risks, resides in its low price, when compared to other herbicides.

A study carried out in Portugal on the contamination of groundwater by pesticides in the regions of "Beira Litoral" and "Ribatejo e Oeste", detected the presence of pesticides in all of the 79 places studied. Atrazine appeared in $70 \%$ of the samples analysed, followed by its metabolites desethylatrazine (DEA) and deisopropylatrazine (DIA), which appeared in 56 and $48 \%$ of the samples. Even though some others pesticides were found, they had lower occurrences [23].

Because of its structure, atrazine is not easily degraded. Its partial degradation is possible by fungus [24] but its total mineralization is not possible by a single microorganism. In fact, it is necessary to have two or more different kind of microorganisms capable of the degradation of the atrazine [25] to achieve total mineralization, although some reports point out that, in some cases even the presence of various microorganisms is not enough to attain this [26]. After the application of a herbicide, a large number of phenomena will dictate the route, which it will follow. These phenomena include retention (adsorption, absorption), transformation (decomposition, degradation), transportation (volatilization, lixiviation, superficial drainage) and the interaction among all these processes. There are also some other aspects that must be taken into consideration, including the structure and properties of the pesticide and environmental characteristics, such as the weather and the localization of the area, among others. For all the pointed above, we may conclude that, the behaviour of pesticides is very complex and is influenced by many different variables.

\section{Supercritical extraction}

There are many techniques available for soil decontamination, all of them having some advantages and disadvantages [27]. Supercritical extraction (SCE) is a technique that presents some important and unique advantages over the other decontamination processes, among which we stand out the low impact in the structure of the soil and on the environment. The first studies on supercritical extraction were carried out by Hanna and Hogart in 1880: they investigated the solubility of many different inorganic salts in solvents under supercritical conditions. In the 1970's, due to the energy crisis, the interest in supercritical extraction has increased, a tendency that continues till nowadays, mainly due to environmental concerns. Supercritical extraction is a unit operation in which a supercritical fluid (SCF), which may be defined as any substance at a temperature and pressure above its critical point [28-30], is used as the extracting solvent $[4,5,7-9,12,13,27]$. SCFs are particularly good solvents because their capacity for dissolving substances is close to that of the liquids, but their viscosity and diffusion coefficient are close to those of the gases, thus improving the transport and mass transfer characteristics of these fluids. Furthermore, since the surface tension of SCFs is equal to zero, these fluids are particularly suitable for the extraction of substances from solid matrices, such as soil. Another advantage in the use of SCFs is the possibility of changing their dissolving power by changing the pressure and/or temperature of the fluid [28], thus allowing the fractional extraction and separation of solutes, and the complete recovery of the solvent by simple pressure adjustments [29]. Of all the SCFs that have been studied, carbon dioxide $\left(\mathrm{CO}_{2}\right)$ is the most commonly used because of its low critical temperature $\left(T_{\mathrm{C}}=304.2 \mathrm{~K}\right)$ and pressure $\left(P_{\mathrm{C}}=7.39 \mathrm{MPa}\right)[27,30,31]$, non-toxicity, availability and low cost.

The supercritical extraction with $\mathrm{CO}_{2}$ has been successfully applied to the removal of a variety of contaminants from soils, even the most persistents to treat, such as PBCs and PAHs. SCE is also being used by EPA as an analytical technique to determine the contents of polycyclic aromatic hydrocarbon (PAHs) and total petroleum hydrocarbons (TPH) in soils. The high potential of SCE as an environmental technique is shown by new applications that are appearing, such as the decontamination of soils with plutonium by SCE, which has been studied by researchers at INEEL (Idaho National Engineering and Environmental Laboratory).

\section{Supercritical extraction in solid matrices}

SCE has received a lot of attention as a potential technique for soil remediation [5-10,12,13,32-35]. The extraction of a substance from a solid matrix requires the following steps: desorption from the matrix, solubilization in the SCF, transport by the extracting fluid and precipitation of the contaminant. All these steps must be taken into consideration when 
trying to implement an experimental protocol for the extraction of contaminants, such as pesticides, from solid matrices by SCE. Therefore, even though the knowledge of the solubility of pesticides in the SCF is important for the design of these processes, it is not enough [27], because variables such as: the interaction between the pesticide and the solid matrix (soil), $\mathrm{pH}$, content of organic matter, and type of soil (content of clay, argyle); and phenomena like van der Waals forces, hydrogen bonds, charge transfer and dipole-induced [36], must be taken into consideration.

Then, the extraction of contaminants from soils is very complex, due to the large number of simultaneous phenomena occurring, and therefore, it is a common practice to begin the study of the applicability of a new technique for soil remediation by studying the extraction of the pollutants from previously contaminated sand, instead of soil.

\section{Experimental study}

The apparatus used to carry out our experimental study is schematically shown in Fig. 1. This system operates in batch mode, and consists of a compressing piston pump (HIP model 68-5.75-15), a stainless steel extraction cell with a volume of $80 \mathrm{~cm}^{3}$, which is a modified version of the cell described by Castelo-Grande and Barbosa [27], and a cold trap to collect the extract. This apparatus can operate for pressures up to $30 \mathrm{MPa}$, and temperatures from 278 till $353 \mathrm{~K}$. The extractor is within an air bath maintained at constant temperature.

\subsection{Chemicals}

The atrazine used in this study has a purity of $98 \%$, and was supplied by Aldrich Chemical Co. (ref. PS-380), as solid matrix media we have used sea-washed sand from Panreac Química S.A. (ref. 21161.211), with two different particle size ranges: $1-2$ and $0.25-0.30 \mathrm{~mm}$. The methanol, used as cleaning solvent, was from Riedel de Haen with a purity greater than $99.9 \%$, and the carbon dioxide was supplied by Air Liquide, with a mole fraction purity greater than 0.99998.

\subsection{Extraction procedures}

The first step is to impregnate the sand with atrazine, which was accomplished by dissolving a predetermined amount of atrazine in methanol, adding this solution to the sand, and allowing the solvent to evaporate during a period of $24 \mathrm{~h}$. After drying, the sand impregnated with atrazine is put into the extractor.

The $\mathrm{CO}_{2}$ is then compressed and fed to the extractor until the desired pressure is reached. The pressure and temperature of the experiment are controlled by a Schaevitz pressure probe and an Omrom temperature controller (with a PT100 probe), respectively. The $\mathrm{CO}_{2}$ is allowed to contact with the sand in the extractor for $2 \mathrm{~h}$. Then (Fig. 1), valve V6 is opened (valves V7 and V8 are kept opened during the experiment), allowing the expansion of the extract into the cold trap, with the corresponding precipitation of the dissolved atrazine. At the end of the experiment, the sampling tube is washed with methanol

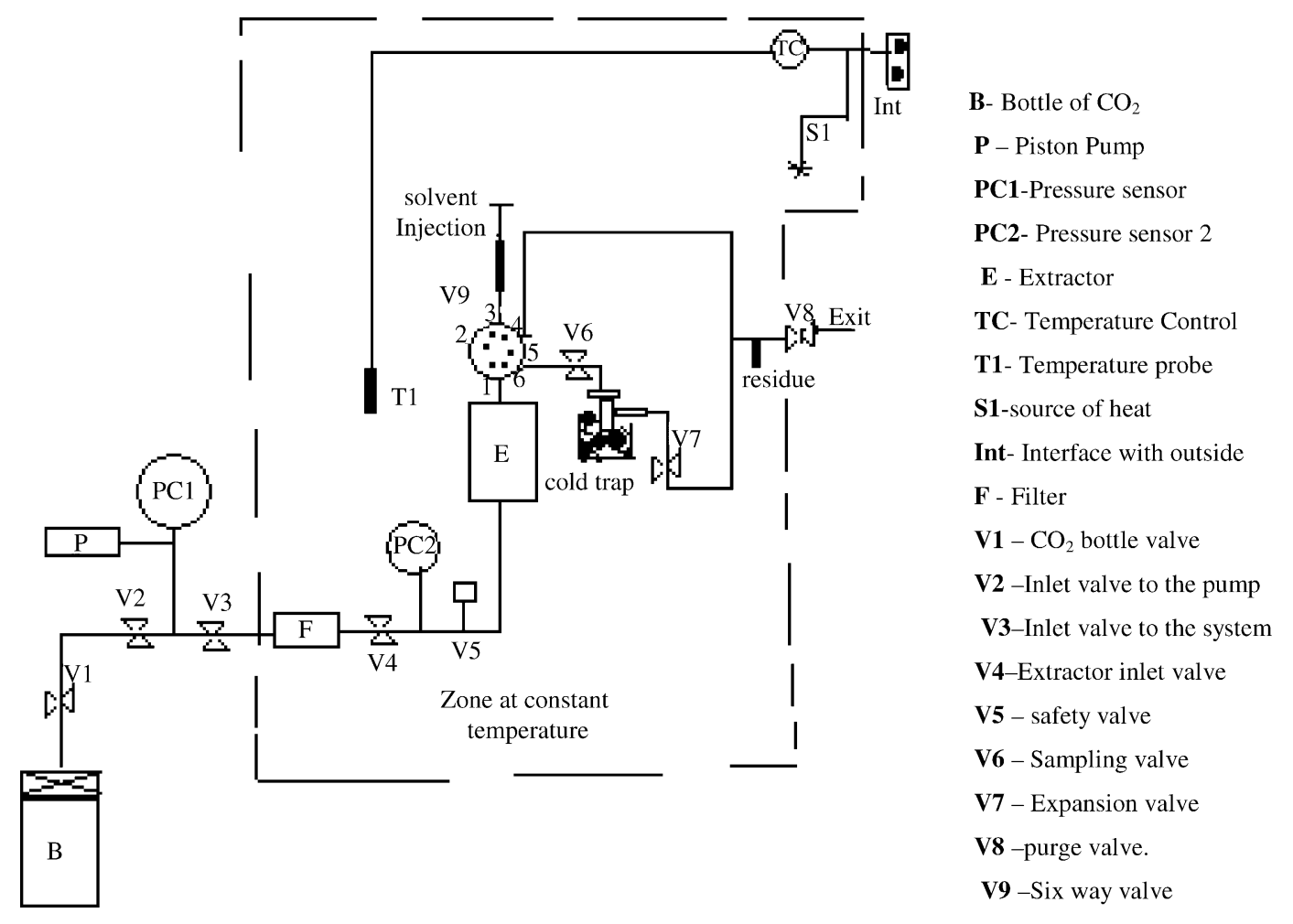

Fig. 1. Schematic representation of the supercritical extraction system. 
to remove possible residues of atrazine. The amount of extracted atrazine is then determined by using reversed-phase high phase liquid chromatography (HPLC, Hewlett Packard model 1050) [37].

This experimental procedure (except the first step) is repeated for the same sand sample until the detected atrazine in the extract reaches negligible levels (according to the initial goals). The total amount of atrazine removed from the sand is obtained by determining the initial and final amount of atrazine present in the sand (the final amount of atrazine in the sand is recovered by washing the sand with methanol).

\subsection{Experimental results}

Experiments were carried out by us at $40^{\circ} \mathrm{C}$ and 215 bar, following the procedure described above. The extractions of atrazine obtained were between 96 and $99 \%$.

\section{Conclusions}

Supercritical extraction has been suggested as a promising technique for soil remediation, in particularly, for the removal of organic compounds, such as: PCBs and PAHs. The main advantage of this technique relatively to other decontamination methods resides in the low impact on the structure of the soil and on the environment, particularly, if no co-solvents are used. Its main drawback is the initial capital cost, which is getting less and less significant with the spreading of this high-pressure technique. The initial investment is also less important relatively to the operating costs when SCE is used in large-scale processes, as in soil remediation.

In this work, a preliminary study on the feasibility of SCE with $\mathrm{CO}_{2}$ for the removal of pesticides from contaminated soils was done. This study was carried out at $40^{\circ} \mathrm{C}$ and 215 bar in a batch extractor, using sand impregnated with atrazine as the solid matrix. The extraction obtained was between 96 and $99 \%$.

These high extractions show that supercritical extraction with carbon dioxide is a promising technique for the remediation of soils contaminated with atrazine, and that the extractor we have designed and the experimental procedure we have developed were successful. Therefore, the next step will be to study the feasibility of the application of the batch SCE process to real soil samples (not only concerning atrazine but also other types of pesticides).

\section{Acknowledgements}

The authors would like to thank Prof. Fernando Concha for his sponsorship regarding the participation in the conference Solid-Liquid Separating System IV. Fundação para a Ciência e a Tecnologia is acknowledged for its Post-Doc sponsorship (Paulo A. Augusto) with reference SFRH/BPD/6964/2001.

\section{References}

[1] C.A. Spadotto, Comportamento e Destino Ambiental de Herbicidas, Comité de Meio Ambiente, Sociedade Brasileira da Ciência das Plantas Daninhas, 2002, p. 1.

[2] V.R. Smith, Ground Water Contamination by Triazine Herbicides, Levels Plain, Canterbury, Report R 93(36), Canterbury Regional Council, Christchurch, 1993, p. 36.

[3] R.J. Hance, Atrazine and Groundwater-Review and Assessment, FAO, Vienna, 1998, p. 63.

[4] T. Castelo-Grande, D. Barbosa, Soil decontamination-a review, Chem. Ind. Environ. IV 1 (2003) 157-165.

[5] B.O. Brady, C.K. Chien-Ping, K. Dooley, F.C. Knopf, R.P. Gambrell, Supercritical extraction of toxic organics from soils, Ind. Eng. Chem. Res. 26 (1987) 261-268.

[6] K.M. Dolley, C.K. Chien-Ping, R.P. Gambrell, R.P. Knopf, The use of entrainers in the supercritical extraction of soils contaminated with hazardous organics, Ind. Eng. Chem. Res. 26 (1989) 20582062.

[7] K.M. Dolley, D. Ghonasgi, F.C. Kopf, R.P. Gambrel, Supercritical $\mathrm{CO}_{2}$ - cosolvent extraction of contaminated soil and sediments, Environ. Prog. 9 (4) (1989) 197-203.

[8] A. Akgerman, C. Erkey, S.M. Ghoreishi, Supercritical extraction of hexachlorobenzene from soil, Ind. Eng. Chem. Res. 31 (1992) 333-339.

[9] L.L. Tavlarides, W. Zhou, G. Anistescu, Supercritical fluid technology from remediation of PCB/PAH-contaminated soil/sediments, in: Proceedings of the 2000 Conference on Hazardous Waste Research, 2000, pp. 239-246.

[10] N. Saim, J.R. Dean, Md.P. Abdullah, Z. Zakaria, Extraction of polycyclic aromatic hydrocarbons from contaminated soil using soxhlet extraction, pressurised and atmospheric microwave-assisted extraction, supercritical fluid extraction and accelerated solvent extraction, J. Chromatogr. 17 (1997) 361-366.

[11] M. Zou, R.K. Trubkey, Z. O'Keil, D.L. Sparks, Study of effects of environmental variables and supercritical fluid extraction parameters on the extractability of pesticides residues from soils using a multivariate optimisation scheme, Trends Anal. Chem. 16 (6) (1997) 351-369.

[12] V. Camel, The determination of pesticide residues and metabolites using supercritical fluid extraction, Trends Anal. Chem. 16 (6) (1997) 351-369.

[13] J.M. Arnaud, Lagadec, D.J. Miller, A.V. Like, S.B. Hawthorne, Pilotscale subcritical water remediation of polycyclic aromatic hydrocarbon and pesticide-contaminated soil, Enviorn. Sci. Technol. 34 (2000) 1542-1548.

[14] WSSA Herbicide Handbook Committee, Herbicide Handbook of the Weed Science Society of America, 6th ed., WSSA, Champaign, IL, 1989.

[15] R.T. Meister (Ed.), Farm Chemicals Handbook'92, Meister Publishing Company, Willoughby, Ohio, 1992.

[16] F.S. Almeida, B. Rodrigues, Guia de Herbicidas, IAPAR, Londrina, 1985 , p. 482

[17] W.H.K.M. Hallenbeck, Cunningham-Burns, Pesticides and Human Health, Springer-Verlag, New York, 1985.

[18] R.E. Gosselin, R.P. Smith, H.C. Hodge, J. Braddock, Clinical Toxicology of Commercial Products, 5th ed., Williams \& Wilkins, Baltimore, MD, 1984.

[19] V.L. Lanchote, Relatório Técnico Enviado ao CNPMA/EMBRAPA, Jaguariúna, 1997.

[20] Parsons, J.M. Witt, Pesticides in Groundwater in the USA. A Report of 1988 Survey of State Lead Agencies, EM8406, Oregon, State University Extension Service, 1989.

[21] W.E. Pereira, C. Rostad, E. Occurrence, Distribution and transport of herbicides and their degradation products in the lower Mississippi river and it tributaries, Environ. Sci. Technol. 26 (1990) 14001406. 
[22] W.E. Pereira, J.L. Domagalki, F.D. Hosteller, Occurrence and accumulation of pesticides and organic contaminants in river sediments, water and clam tissues from San Joaquin river and tributaries, Environ. Toxicol. Chem. 5 (2) (1996) 172-180.

[23] S. Batista, E. Silva, S. Galhardo, P. Viana, J.M. Cerjeira, Evolution of pesticides contamination of groundwater in two agriculture areas of Portugal, Int. J. Environ. Anal. Chem. 82 (8/9) (2001) 601-609.

[24] D. Levanon, Roles of fungi and bacteria in the mineralization of pesticides atrazine, alachlor, malathion and carbonfuranin soil, Soil Biol. Biochem. 25 (8) (1993) 1097-1105.

[25] M. Rasodevich, S. Traina, Y. Hao, O.H. Tuovinen, Degradation and mineralization of atrazine by soil bacterium isolate, Appl. Environ. Microbiol. 61 (1995) 297-302.

[26] R. Korpraditskul, A. Katayama, S. Kuwatsuka, Degradation of atrazine by soil bacteria in stationary phase, J. Pesticide Sci. 28 (1993) 293-298.

[27] T. Castelo-Grande, D. Barbosa, Soil decontamination by supercritical extraction, Electr. J. Enviorn. Agric. Food Chem. 2 (2) (2003).

[28] E. Martinez de la Ossa, G.M.A. Serrano, Extraction con fluidos supercriticos: fundamentos, Ingeniería Química (1998) 169175.

[29] I. Medina, J.L. Bueno, J. Coca, Extraction supercritical: fundamentos y aplicationes, Ingenería Química (1998) 231-234.
[30] C. Pereyra Lopez, A. Molero Gomez, E. Martinez de la Ossa, Extraccion supercritica con dioxido de carbono, Ingeneiría Química (1990) 181-185.

[31] W. Glen, L. David, Tomasko, J. Chalmers, Dynamics of linked supercritical extraction-biodegradation process for organic waste, Chem. Eng. Sci. 53 (2) (1998) 189-201.

[32] R. Marr, T. Gamse, Use of supercritical fluids for different processes including new developments-a review, Chem. Eng. Process. 39 (2000) 19-28.

[33] J.R. Dean, G. Xiong, Extraction of organic pollutants from environmental matrices: selection of extraction technique, Trends Anal. Chem. 9 (9) (2000) 553-564.

[34] G.A. Montero, K.B. Schenelle, T.D. Giorgio, Supercritical fluid extraction of contaminated soil, J. Enviorn. Sci. Health A 32 (2) (1997) $481-495$.

[35] A. Laitinen, A. Michaux, O. Aaltonen, Soil cleaning by carbon dioxide extraction: a review, Environ. Technol. 15 (1994) 727-751.

[36] R.T. Kurnik, R.C. Reid, Solubility of solid mixtures in supercritical fluids, Fluid Phase Equilib. 8 (1982) 93-105.

[37] I.L. Barnabas, J.R. Dean, S.M. Hitchen, S.P. Owen, Selective extraction of organochlorine and organophosphorus pesticides using a combined solid phase extraction-supercritical fluid extraction approach, Anal. Chim. Acta 291 (1994) 261-267. 